\title{
'You can talk about condoms [with younger men] while older men ... beat you for that': Young women's perceptions of gender-based violence within intergenerational relationships in South Africa
}

\author{
N Lince-Deroche, ${ }^{1}$ MPH, MIA, PhD; T Shochet, ${ }^{2}$ MPH, PhD; J Sibeko, ${ }^{1}$ MPsy; L Mdlopane, ${ }^{1}$ MSoc; S Pato; ${ }^{1}$ Q $S$ Makhubele; ${ }^{3}$ \\ T Bessenaar, ${ }^{1}$ MPsy, DLitt et Phil
}

${ }^{1}$ Ibis Reproductive Health, Johannesburg, South Africa

${ }^{2}$ Gynuity Health Projects, New York, NY, USA

${ }^{3}$ Valoyi Traditional Authority Trust, N'wamitwa, South Africa

Corresponding author: N Lince-Deroche (naomi.lince.deroche@gmail.com)

\begin{abstract}
Background. In South Africa (SA), HIV prevalence is significantly higher in young women than in young men. Intergenerational relationships and women's dependence on men are known HIV risks.

Objectives. To qualitatively explore young women's perceptions and experiences of dating younger and older men and their perceived risks for gender-based violence.

Methods. From July to September 2011, we conducted eight focus group discussions (FGDs) and 20 in-depth interviews (IDIs) with young women aged 15 - 24 years. Women were recruited from two SA communities: one urban location in Gauteng Province and one rural location in Limpopo Province. All interviews were recorded, transcribed and translated from local languages into English. The study team then analysed the transcripts thematically, using an inductive approach, with ATLAS-ti (v6.2) software.

Results. In total, 110 young women participated, 20 of them in both the FGDs and the IDIs. Young men were viewed by the participants as immature, unable to provide financially and likely to be HIV-positive, although young women sought out young men for 'love', mutual understanding and intimacy. In contrast, older men were perceived as easy to respect, ready for marriage and able to provide for women's needs. Young women sought older men as providers, but acknowledged that older men were more likely to be violent and that discussing sexual and reproductive health and HIV with them was difficult. Young women expressed the belief that if a man was providing for them financially, he had 'the right' to use violence.

Conclusions. The interviews highlighted young women's mixed views on the 'value' of older v. younger partners, and the perceived and real risks of violence in intergenerational relationships. There is a need for interventions addressing power dynamics in relationships, including healthy communication. However, to address young women's vulnerability to violence, ultimately young women and their families need access to economic opportunities that reduce dependence on transactional relationships.
\end{abstract}

S Afr Med J 2018;108(8):682-686. DOI:10.7196/SAMJ.2018.v108i8.12794

South Africa (SA) has one of the highest adult HIV prevalence rates globally at 19.6\%; an estimated 7 million people are currently living with HIV in the country. ${ }^{[1]}$ The prevalence of HIV infection is disproportionately higher in young women than in their male counterparts. HIV prevalence among women aged $20-24$ years is $\sim 13.1 \%$, as opposed to $\sim 4 \%$ among men in the same age range. ${ }^{[2]}$

Gender-based violence (GBV) is also a serious problem in SA, intimately linked to the HIV epidemic. In local studies, $>7 \%$ of women attending an antenatal clinic in an urban area ${ }^{[3]}$ and $>15 \%$ of women in a rural area ${ }^{[4]}$ reported that their first sexual experience was forced. Abusive partners are more likely than those who are not abusive to have multiple sexual partners and to be infected with HIV, and are less likely to use condoms. ${ }^{[4,5]}$ Further, fear of violence may not only hinder condom use but can also prevent a woman from seeking HIV counselling or treatment. Women who experience intimate partner violence are at increased risk of unintended pregnancy and sexually transmitted diseases. ${ }^{[6,7]}$

Intergenerational relationships and women's dependence on men have been identified as significant risk factors for both GBV and HIV. ${ }^{[8,9]}$ Relationships with older men have been associated with unsafe sexual behaviour, low condom use and an increased risk of HIV infection. ${ }^{[10-12]}$ In SA, several factors contribute to a high prevalence of intergenerational relationships. It has been reported that high levels of poverty and lack of access to education, health services and employment often push women and girls into agedisparate sex for potential economic gain. ${ }^{[10]}$

\section{Objectives}

To explore young women's perceptions and experiences of dating younger and older men, their ability to communicate with partners about sexual health issues, including HIV, and their perceived risks of experiencing GBV.

\section{Methods}

Between July and September 2011, we conducted qualitative data collection from young women in two locations in SA: one urban site in Gauteng Province and one rural site in Limpopo Province. In both locations, our study team used convenience sampling to approach and recruit young women from the general community, public clinics, shopping malls and schools. Young women were eligible to 
join if they were 15 - 24 years old, lived in the study communities, and spoke either isiZulu (in the urban site) or Xitsonga (in the rural site). Participants aged 18 - 24 consented to participate. Participants aged $<18$ provided their assent, and their parents/guardians provided consent (in accordance with local ethics regulations). Approval for the study was obtained from the Human Research Ethics Committee at the University of the Witwatersrand, Johannesburg (ref. no. M110327) and Allendale Institutional Review Board in the USA. Participants received ZAR100 reimbursement (roughly equivalent to USD12.50 during the study period) for their time and transportation costs to and from the research venue.

Data collection consisted of focus group discussions (FGDs) and in-depth interviews (IDIs). The FGDs were conducted as one component within 2-day participatory research sessions. Each FGD was conducted with $\sim 10-15$ young women. The research sessions included an FGD, body mapping and community mapping exercises. Participants who were $<18$ years of age participated in separate sessions from those aged 18 - 24. The FGDs were designed to generate discussion of young women's knowledge, attitudes and experiences regarding teenage pregnancy, HIV, GBV, and other sexual and reproductive health issues. Relationships with male partners were a special focus, including both the ability to communicate about sexual and reproductive health issues with male partners and differences between older and younger partners.

The IDIs occurred after the FGDs on a separate day. Young women were eligible for the IDIs if they had participated in one of the 2-day research sessions. The study team purposefully selected both young women who had been pregnant and those who had never been pregnant. While these interviews were meant to explore issues pertaining to teenage pregnancy, GBV was raised by the young woman in some of these exchanges. In this article, we present results from the FGDs and IDIs pertaining to GBV and relationships with male partners. We also include results pertaining to young women's ability to talk about sexual and reproductive health services with their partners and their ability to use contraception or test for HIV with their partners.

All interviews were recorded, transcribed and translated from local languages into English. The study team then analysed the transcripts thematically, using an inductive approach. Analysis was conducted using ATLAS-ti v6.2 (ATLAS.ti Scientific Software Development $\mathrm{GmbH}$, Germany).

\section{Results}

We conducted a total of eight FGDs: two with 15 - 17-year-olds and two with 18 - 24-year-olds in each of the two communities. A total of 110 young women participated in the FGDs (50 from the urban site and 60 from the rural site). In addition, we conducted 20 IDIs, 10 from within each community. In each community, five of the IDI participants had previously been pregnant. The age range of the IDI participants was $17-23$ years at the urban site and $19-24$ years at the rural site.

\section{Communication regarding contraception with older v. younger men}

In all the groups, responses to questions regarding whether young women can talk to their partners about contraception or family planning varied. Some respondents indicated that it was easy to talk to guys their age and that they can 'even go to the clinic with you', but many respondents disagreed. They indicated that many men believe that when women use family planning it adversely affects the man's health, or that it will adversely affect the woman's health and make sex less pleasurable. This is illustrated in the following quotes:
'[Men say] when they use condoms, it hurts them.' 'The injection [that women use for contraception] makes their sex weak.' (Rural respondent aged 15 - 17)

'The boys, they say you give birth to water when you inject [contraceptives].' (Rural respondent aged 18 - 24)

'Others say it's not nice having sex while you are preventing [i.e. using contraception], they say you have lots of water coming out of your vagina while having sex.' (Rural respondent aged 15 - 17)

The young women indicated that owing to these concerns, even if unfounded, men discourage their partners from using contraceptives, so young women avoid using them; or if they do, they prefer not to tell their partners. Some of the older respondents expressed the belief that using family planning (referred to as 'prevention') was their own responsibility and that their partners shouldn't know about it. In fact, telling one's partner about use of family planning was noted to have potentially negative effects. Both younger and older participants reported that many men would think that they 'sleep around' if they told them they use family planning. One older woman said she wouldn't tell her boyfriend about her use of contraception because then he would refuse to use a condom and she would 'have AIDS' (urban respondent aged 18 - 24).

Despite many comments about preferences for not telling one's partner, when asked about potential differences in communication with older $v$. younger men, several older respondents expressed the opinion that it is easier to tell younger partners than older ones about use of family planning, in part because older partners are more interested in having a baby and they 'expect you to have a child for them' (rural respondent aged 18 - 24).

In contrast to reports in the FGD discussions, almost all the IDI participants said that they did discuss family planning with their partners. However, in most cases it was part of a broader conversation about avoiding both pregnancy and HIV:

'Yes we do sit down and talk about the hardships and HIV and how it can affect us and how important it is to protect yourself when having sex, so I tell him that when he is out drinking and decides to have sex with another woman he must use a condom. And when he comes home to visit I tell him we should protect ourselves as we are not ready for another child.' (Rural respondent aged 22)

'We talk about the dangers of having unprotected sex which may lead to HIV and unplanned pregnancy. I also tell my boyfriend that I do not want to have another baby before marriage.' (Urban respondent aged 23)

\section{Communication regarding HIV and condom use with older $v$. younger men}

The respondents gave mixed responses regarding whether young women can easily communicate with their partners about HIV and condom use. In some cases, trusting your partner or 'being in love' were suggested as reasons that made talking easier. Most said that it is possible to talk to men their age about HIV and condoms, whereas it is very difficult to talk to older men. Several respondents expressed fear of violent responses if they were to ask older partners to use condoms or test for HIV:

'You can talk about condoms [with younger men] while older men ... beat you for that.' (Rural respondent aged 18 - 24)

'With the older guys it is harder because sometimes you are scared to tell him to use a condom because he might hit you. As to the younger guy, you are able to tell him let's use one.' (Rural respondent aged 18 -24)

'You are just scared that you may offend them because they are older and then they end up hitting you.' (Urban respondent aged 15 - 17) 
In almost all cases, the respondents felt that if a conversation about condom use or HIV testing happens, it is the woman who must initiate it. One respondent justified this, saying 'most guys do not like using condoms'. Another respondent summed up the importance of getting tested no matter what:

'Okay, I do admit you can trust him if he is your boyfriend, but others can't be "one-woman man". So what I can say is that you must always test.' (Urban respondent aged 15 - 17)

The young women who participated in the IDIs also had mixed responses when it came to discussing condom use. While most said they had conversations with their partners about the need for condoms, several reported that it was hard to get them to use condoms. They noted that receiving financial support from one's partner can make this especially difficult:

'It's harder to negotiate using a condom more especially when your partner gives you money. Having sex with them is like a payment.' (Urban respondent aged 17)

Moreover, several participants expressed concerns about their partners' fidelity and lack of condom use in other relationships:

'I even tell him if he feels like cheating on me he should condomise because I will not cheat on him ... I would use a condom because when I tell him to use a condom he refuses so elsewhere he must be refusing as well.' (Rural respondent aged 22)

\section{Young women's preferences for older or younger men}

When asked who young women prefer to date, there were mixed responses in favour of both younger and older partners. Many of the respondents noted that they wanted a partner that they 'respected' and emphasised that respect for one's male partner is important in order to avoid violence in relationships. Older men were perceived by young women as easy to respect, ready for marriage and able to provide for women's needs:

Facilitator: 'So when you guys are not the same age, you won't fight? Is that what you are saying?'

Young woman: 'Yes because you guys have respect for each other, and you will have respect for him as well.' (Rural respondent aged $15-17)$

That said, the young women acknowledged that they do not have power in relationships with older men, and that they must obey or risk violence or abandonment. They said that they experienced more difficulty discussing sexual and reproductive health and HIV with older men than younger men. They also expressed being particularly at risk for violence if they refused sex, proposed condom use, or questioned an older man regarding suspected infidelity. The young women also expressed a belief that if a man is providing for their financial needs, he has the right to use violence.

Financial support was noted as a key factor in choosing one's partner. Several respondents mentioned that their family members, in particular their mothers, preferred them to have older boyfriends who can provide for their families:

'He [the second and older boyfriend] gives me whatever I want. I stop asking stuff from my mother. I will tell her to stop providing [for] me. She will not say, no my baby, I will provide [for] you.' (Urban respondent aged 18 - 24)

While the in-depth interviewees were not asked directly about partners' age, a few of the young women spontaneously discussed this issue. They reported that older partners are often sought out for financial support and in return, 'they will force you to have a child for them to support you and give you money' (urban respondent aged 23).

In contrast to older men, who were seen as providers, younger men were viewed as immature and unable to provide for women financially:

'It is very rare a guy your age can provide such [things] that is why we want older men, like men with families.' (Rural respondent aged 18 - 24)

'Yes, there are people who date older men: sugar daddies. They are expecting them to buy them expensive gifts and clothes, while younger men are always broke. Younger boys will be sending you "call-backs" [a reference to a practice in SA where one can send a text message requesting that the receiver call the sender] when an older man will send you airtime.' (Rural respondent aged 15 - 17)

\section{Community-level communication regarding GBV}

At the urban site, the FGD respondents indicated that the people in their community are aware of the level of GBV and discuss it openly. One participant from the older age group said that sometimes '[they] are beating you in the street so that people can see you'. In contrast, at the rural site the respondents indicated that people generally don't talk about GBV; they said that their mothers fear for their security and are afraid of what people will say. The rural respondents expressed feelings that if a man is providing food for the family, the wife and daughter must be silent about any abuse and not risk losing his support.

\section{Young women's ability to avoid GBV}

Respondents in both locations mentioned that women can report violence to the police, but they said that was for extreme cases (and added that often the police will not follow up), and that the best way to avoid violence is for the woman to obey:

'When your boyfriend calls you to come see him, you must go and speak softly to him.' (Rural respondent aged 15 - 17)

A few of the respondents suggested that if violence is recurring, the young woman should 'dump' her boyfriend, but other respondents argued that it is not easy to leave a violent partner. Some stated they would give him another chance because 'If you love someone you cannot just forget about him - just like that' (urban respondent aged 18 - 24).

Several respondents identified their own infidelity as a cause for abuse and said that the only way to avoid being abused was to 'stop cheating' (urban respondent aged 18 - 24). However, some older participants thought that abuse could be prevented by open communication, for example to 'sit down and set your goals and know what you want out of life' (rural respondent aged 18 - 24).

The young women in the IDIs all commented on ways in which women could avoid being abused. One repeated theme was good communication between the couple:

'I think it is to have an understanding and be able to listen to each other and as a man make time to listen to your partner when she talks, the problem starts when one party wants to be the other person's boss.' (Rural respondent aged 22)

'The first time you meet a new partner, you need to set up the rules to state categorically what you like and what you don't like, and you also need a lot of communication between the two of you. When you guys have an issue, you need to address it the both of you.' (Rural respondent aged 22)

Other important factors that were mentioned by these women were the importance of being faithful, 'because if the partner finds out they are 
unfaithful, he/she will get violent' (rural respondent aged 20), as well as the importance of choosing the right moment for communication:

'Young women must not disagree with their partners right there ... when discussing things, they must wait for a particular time when the mood is right and disagree with the issue. Otherwise she will continue to get beaten up.' (Rural respondent aged 22)

\section{Discussion}

This study provides a qualitative illustration of young women's perceptions of risk of violence as well as the social and economic contributors to and risks of choosing older or younger partners. Decision-making regarding relationships by young women in the study was influenced by several factors. Although they recognised an increased risk of violence with older partners, some young women expressed a willingness to tolerate the risk, stating that older men would be easier to 'respect' and more likely to be able to provide for their financial needs. The young women were aware of the power imbalances in many relationships, in part necessitated by the need for financial support - for themselves and for their families.

The need for financial support and the sense of women being resigned to experiencing violence or lack of power in their relationships as a result of needing such support seemed more acute in the rural setting. Although opportunities for employment or women's financial independence were limited in both settings, they may have been more limited at the rural site. In this setting, women were more likely to be expected to adhere to traditional roles in the household, and the closest city - where more employment opportunities might exist - was $\sim 30$ minutes away using public transport.

Communication regarding sexual and reproductive health was more difficult with older men, but appeared challenging with younger men as well. Discussion of contraception was sometimes difficult owing to male partners' (mis)perceptions of risks associated with its use and their opinions regarding women who chose to use contraception. Interestingly, however, some of the study participants felt that contraception was their responsibility and did not require discussion with their partner. Responses were mixed regarding the ease of discussing HIV and condoms with one's partner. Some were able to tell their partner to use condoms with other women. Nearly all the IDI participants had discussed condoms with their partner(s). However, it seemed clear to the FGD and IDI respondents that discussions of condom use - if possible - would not necessarily lead to safer practices.

Perhaps not unexpectedly, the young women expressed few strategies for completely avoiding violence in their relationships. At the urban site, GBV was seen to be commonplace, an expected, or normalised, attribute of adult relationships. At the rural site, it was also commonplace, but was not spoken about openly. Many of the study participants appeared to blame themselves for any GBV experiences, and many felt that it was their responsibility to avoid violence by behaving in an 'acceptable' way. Some felt that communication was key, but this involved toning down their expectations or picking their battles carefully. 'Respect' for one's partner also emerged as a prevention strategy. Unfortunately, although some of the respondents did suggest leaving an abusive partner, they were not in the majority. Very few of the respondents objectively expressed the view that GBV was intrinsically wrong and should not be tolerated.

\section{Study limitations}

The study is limited in terms of its generalisability in that it included qualitative interviews with a small number of women. However, qualitative research generally aims to produce context and in-depth understanding rather than generalisable results based on statistical methods. For this study, the results provide insight into the decisionmaking of young women in the two communities and the influence of personal, structural and community-level factors on their GBV risk.

\section{Conclusions}

Addressing GBV in communities where poverty and gender inequality are rife will require widespread effort addressing not only individual beliefs and behaviours but also the underlying structural issues, such as poverty and employment opportunities, that lead young women to accept dependent roles. Young women and their families must be helped to understand the potential longer-term implications of such power imbalances; however, the short-term concerns regarding meeting basic needs cannot be forgotten.

Young women are less likely than older women to be economically independent and may face significant challenges when negotiating the terms of sexual relationships. ${ }^{[1,13]}$ Programmes designed to integrate GBV- and HIV-related services have been recommended owing to the overlapping risk factors for these two social issues. ${ }^{[14]}$ Globally there has been a strong emphasis of late for HIV prevention efforts to focus on girls and young women. ${ }^{[15]}$ Many of these efforts stress biomedical interventions, such as pre-exposure prophylaxis; however, there is growing recognition of the importance of interventions addressing psychosocial and structural drivers of HIV infection. These efforts could further benefit from addressing co-factors specific for GBV, including poor communication and negotiation skills and young women's economic dependence on older men.

There are examples of successful interventions for addressing violence against women and girls, including in SA, the majority of which focus on community-based communication and empowerment. The Prevention in Action study conducted in two urban areas in SA evaluated community-based training and awareness raising on GBV coupled with community-led action and showed self-reported transformation among the participants. ${ }^{[16]}$ Stepping Stones, another community-based participatory programme evaluated in a rural area in the country, reduced perpetration of violence among men. ${ }^{[17]} \mathrm{A}$ randomised trial where rural women's economic vulnerabilities were addressed through loans led to reduced experiences of violence. ${ }^{[18]}$ Additional ongoing studies in SA, currently part of the What Works to Prevent Violence initiative, ${ }^{[19]}$ will provide further insight as to possible interventions. Civil society and government in SA should look to proven interventions and the increasing public awareness and general disapproval of GBV - particularly in many urban areas - as an opportunity for immediate action.

Acknowledgements. We thank Charlotte Ngobeni, Ace Silelo Mabunda, Khosi Mazibuko and the representatives of each community for their assistance with implementing the study.

Author contributions. NL-D conceptualised the study and analysis plan. SP and QSM led recruitment, data collection and community engagement activities. JS, LM, SP and NL-D contributed to study oversight, data management and coding, and analysis. NL-D and TS drafted the manuscript, and all authors provided comments and approval for the final version.

Funding. This work was generously funded by the Ford Foundation's Office for Southern Africa.

Conflicts of interest. None.

1. Joint United Nations Programme on HIV/AIDS (UNAIDS). South Africa: HIV and AIDS estimates (2015). 2016. http://www.unaids.org/en/regionscountries/countries/southafrica (accessed 6 November 2016).

2. Joint United Nations Programme on HIV/AIDS (UNAIDS). South Africa HIV Epidemic Profile.

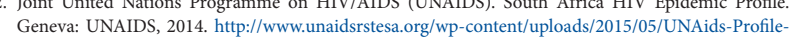
South-Africa.pdf-18-Feb.pdf (accessed 6 November 2016). 
3. Dunkle KL, Jewkes RK, Brown HC, et al. Prevalence and patterns of gender-based violence and revictimization among women attending antenatal clinics in Soweto, South Africa. Am J Epidemiol 2004;160(3):230-239. https://doi.org/10.1093/aje/kwh194

4. Jewkes R, Dunkle K, Nduna M, et al. Factors associated with HIV sero-status in young rural South African women: Connections between intimate partner violence and HIV. Int J Epidemiol 2006;35(6):1461-1468. https://doi.org/10.1093/ije/dyl218

5. World Health Organization. WHO Multi-country Study on Women's Health and Domestic Violence against Women. Geneva: WHO, 2005

6. Jewkes R, Vundule C, Maforah F, Jordaan E. Relationship dynamics and teenage pregnancy in South Africa. Soc Sci Med 2001;52(5):733-744. https://doi.org/10.1016/s0277-9536(00)00177-5

7. Campbell JC. Health consequences of intimate partner violence. Lancet 2002;359(9314):1331-1336. https://doi.org/10.1016/S0140-6736(02)08336-8

8. Decker $\mathrm{M}$, Seage $\mathrm{G}$, Hemenway $\mathrm{D}$, et al. Intimate partner violence functions as both a risk marker and risk factor for women's HIV infection: Findings from Indian husband-wife dyads. J Acquir Immune Defic Syndr 2009;51(5):593-600. https://doi.org/10.1097/qai.0b013e3181a255d6

9. Jewkes R, Morrell R. Gender and sexuality: Emerging perspectives from the heterosexual epidemic in South Africa and implications for HIV risk and prevention. J Int AIDS Soc 2010;13(6):1-11. http:// archive.biomedcentral.com/1758-2652/13/6/

10. Leclerc-Madlala S. Why young women in southern Africa are going for riskier, older men. ResearchGate. 2010. https://www.researchgate.net/publication/254892464_Why_young_women_in_ southern_Africa_are_going_for_riskier_older_men (accessed 6 November 2016).

11. Luke N. Age and economic asymmetries in the sexual relationships of adolescent girls in sub-Saharan Africa. Stud Fam Plann 2003;34(2):67-86. https://doi.org/10.1111/j.1728-4465.2003.00067.x

12. Evans M, Risher K, Zungu N, et al. Age-disparate sex and HIV risk for young women from 2002 to 2012 in South Africa. J Int AIDS Soc 2016;19(1):1-16. https://doi.org/10.7448/IAS.19.1.21310
13. Bohmer L, Kirumira E. Access to Reproductive Health Services: Participatory Research with Adolescents for Control of STDs. Los Angeles: Pacific Institute for Women's Health, 2000.

14. Khan A. Gender-based Violence and HIV: A Program Guide for Integrating Gender-based Violence Kreve Prevention and Response in PEPAR Programs (USAID's AIDS Support and Technical Assistance Development, 2011. Development, 201

15. Fleischman J, Peck K, Friedman S. Addressing HIV risk in adolescent girls and young women. April 2015. http://csis.org/files/publication/150410_Fleischman_HIVAdolescentGirls_Web.pdf (accessed 6 November 2016).

16. Parker W. Prevention in Action: A Model for Social Mobilization to Prevent Violence against Women San Diego, Calif.: Project Concern International, 2013.

17. Jewkes R, Nduna M, Levin J, et al. Impact of Stepping Stones on incidence of HIV and HSV-2 and sexual behaviour in rural South Africa: Cluster randomised controlled trial. BMJ 2008;337:a506. https://doi.org/10.1136/bmi.a506

18. Pronyk PM, Hargreaves JR, Kim JC, et al. Effect of a structural intervention for the prevention of intimate partner violence and HIV in rural South Africa: Results of a cluster randomized trial. Lancet 2006;368(9551):1973-1983. https://doi.org/10.1016/s0140-6736(06)69744-4

19. UK Aid. What Works to Prevent Violence: The Global Programme to Prevent Violence Against Women and Girls. http://www.whatworks.co.za/about/global-programme (accessed 22 December 2017).

Accepted 1 March 2018. 